\title{
Analysis of the distribution of temperature fields in the braked railway wheel
}

\author{
Andrej Suchánek ${ }^{1, *}$, Jozef Harušinec ${ }^{1}$, Mária Loulová ${ }^{1}$, Peter Strážovec $^{1}$ \\ ${ }^{1}$ University of Žilina, Faculty of Mechanical Engineering, Department of Transport and Handling \\ Machines, Univerzitná 8215/1, 01026 Žilina, Slovak Republic
}

\begin{abstract}
The article deals with detection of reduced stress in a braked railway wheel, based on thermal transient analysis on virtual models, which influence the characteristics of the railway wheels. Structural analysis was performed by means of the ANSYS Multiphysics program system package. Thermal transient analysis deals with detection of temperature fields which are a result of braking by brake block. The applied heat flux represents the heat generated by friction of brake block. It is applied to a quarter model of the wheel to speed up the calculation. This analysis simulates two braking processes with subsequent cooling. Distribution of the equivalent stress was detected in the railway wheel cross section, at selected points. The input parameters were taken from the thermal transient analysis. These equivalent stresses result from thermal load.
\end{abstract}

Keywords: railway wheel, brake block, structural analysis

\section{Introduction}

The brake system of railway vehicles is an important subsystem in terms of driving safety. Investigated issue is process of non-stationary temperature fields spreading, generated by the braking railway vehicles The thermal load on the wheels has a significant rate on the influences due braking by the brakes, that lead to wear - modification and damage of the wheel tread $[5,15,21]$. In the braking process we have to take into account the fact, that the wheel is a brake block not only overheated at the point of their contact but also loaded with normal and tangential stress, which is the source and the necessary precondition for the braking process creation $[7,14]$. With regard to the braking design and the braking mechanism, we include braking brakes between the adhesive brakes because the braking effect of the vehicle itself with respect to the track is realized by contacting the wheel and the rail via the contact patch $[12,18]$.

Researches must pay attention to studying the effects of thermal and mechanical loading wheels of railway vehicles of reasons: the operation of vehicles, protection of life and health of the traveling public, reliable transport material and minimizing the negative effects of rail traffic on the environment $[10,25]$.

\footnotetext{
* Corresponding author: andrej.suchanek@fstroj.uniza.sk

Reviewers: Bohuš Leitner, Milan Žmindák
} 
Article deals with the detection of residual stress in a braked railway wheel based on thermal transient analysis. Railway wheel is loaded by heat flux, which is applied on the contact surface. This topic is discussed in more detail in mentioned literature and references $[1-4,2,3,4,6,11,19,22]$.

\section{Residual stresses}

In design and computational practice, a material is usually considered as homogeneous isotropic continuum [9].

The deformation of bodies and stress occurrence happens mainly due to [17, 23]:

1. Mutual power action of bodies.

2. Action of field of temperature:

- homogenous (tension appears when thermal dilatation of body is restrained),

- non - homogenous (tension appears even if thermal dilatation of body is free).

If the plasticity condition is not satisfied, active tensions occur in elastic area and after removing of causes of their formation it completely disappear.

If formation of elastic plastic state arises in any point of a body, then after removing of formation causes (power, distortive and thermal), some residual stresses stay in a body [13, 20, 24].

Certain residual state of stress remains almost always in structural materials due to their production technology.

Residual stresses can be:

1. Helpful - e.g. peening is introduced compressive stresses in the surface layer, leading to prolongation of lifetime.

2. Harmful - cracking, corrosion stress, reduce fatigue limit or brittle fracture resistance (especially negative effect on tensile residual stresses).

High tensile stresses, induced, for example in the area of welds cools and phase transformations, may cause rupture even without additional external forces [8].

\section{ANSYS program package}

The program ANSYS (Fig. 1) uses the finite element method. Modeling of the finite element method belongs to the group of numerical methods. This method develops due to the constant increase in computing power. Its core is the discretization of bodies on the files of finite elements. These elements form analogue after parts field that can be mathematically written [16].

The ANSYS program is generally nonlinear, multiphysics program including structural and thermodynamic analysis, analysis of flow continuum, analysis electrostatic and electromagnetic fields, and acoustic analysis. All these analyzes can be performed individually, but thanks ANSYS multiphysics conceived program can also be included in one common analysis. [10]. The ANSYS program allows you to not only check calculations, but also enables optimization and sensitivity analysis due to parameterized computational models, as well as the calculations of reliability.

ANSYS Mechanical product is intended to simulate the structural and thermodynamic tasks. The program includes the complete set of linear and nonlinear simulation with using linear and non-linear elements, material models, and contact non-linear algorithms. 


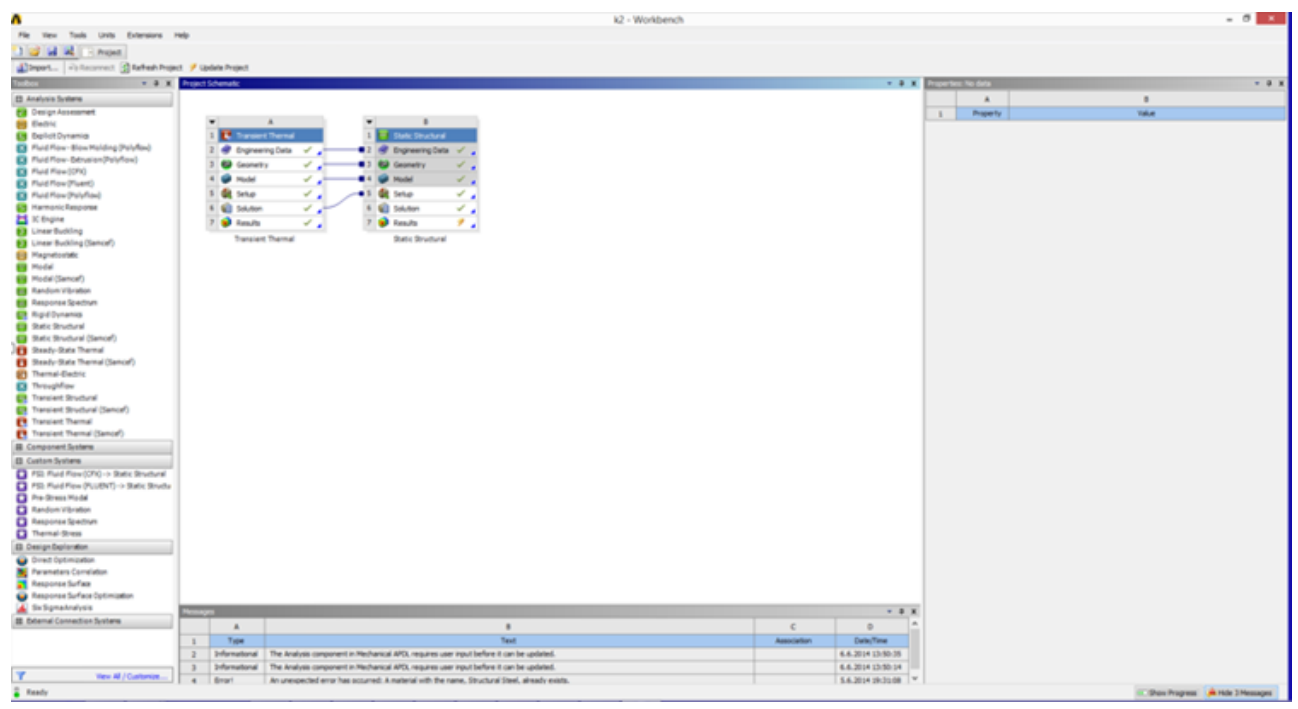

Fig. 1. ANSYS Workbench program system environment

\section{Transient thermal analysis in ANSYS program}

The problem simulates heating of the railway wheel tread. The railway wheel is braked by the brake block. The heat generated by the brake pad friction represents a heat flow of 32 $\mathrm{kW}$ (cast iron block) and $38 \mathrm{~kW}$ (composite block). This analysis simulates two braking for 100 seconds when the heat flow is applied to the wheel tread. Railway wheel cools for 300 seconds; after the first braking and 1000 seconds after the second braking. The value of heat flux is then zero. The composite brake block has a worse heat dissipation than cast iron and therefore heats the wheel's surface more heavily. The applied heat flux in the composite block is greater than that of the cast iron block.

A quarter model of railway wheel was created using CATIA program and imported into ANSYS program.

\subsection{The definition of material properties}

Railway wheel is made of steel DIN 40Mn4. The thermal properties used in the simulation are shown in Tab 1.

Table 1. Thermal properties of materials

\begin{tabular}{|c|c|c|}
\hline Properties & Railway wheel & Air \\
\hline Density $\rho\left[\mathrm{kg} \cdot \mathrm{m}^{-3}\right]$ & 7850 & 1.170 \\
\hline Heat capacity $C p\left[\mathrm{~J} \cdot \mathrm{kg}-1 . \mathrm{K}^{-1}\right]$ & 486 & 1100 \\
\hline Thermal coductivity $k\left[\mathrm{~W} \cdot \mathrm{m}^{-1} \cdot \mathrm{K}^{-1}\right]$ & 52 & 0.026 \\
\hline Emissivity - wheel tread[-] & 0.20 & - \\
\hline Emissivity - other surfaces & 0.80 & $1.8 .10^{-5}$ \\
\hline Dynamic viscosity $[$ Pa.s $]$ & - & \\
\hline
\end{tabular}




\subsection{Definition of boundary conditions}

A quarter model was used because of the acceleration calculation. The symmetry has been applied to the model.

The values of the heat flux (power) $32 \mathrm{~kW}$ (cast iron block) and $38 \mathrm{~kW}$ (composite block), which is applied to the wheel tread (Fig. 3) are shown in table 2. Dependence heat flux to time is shown in Fig. 2. Simulation did not involve wheel rotation or thermal expansion of the wheel.

Table 2. Dependence heat flux to time

\begin{tabular}{|c|c|c|}
\hline Step & Time $[\mathbf{s}]$ & Heat flux $[\mathbf{W}]$ \\
\hline 1 & 0 & 0 \\
\hline 1 & 10 & $32000(38000)$ \\
\hline 2 & 100 & $32000(38000)$ \\
\hline 3 & 101 & 0 \\
\hline 4 & 400 & 0 \\
\hline 5 & 410 & $32000(38000)$ \\
\hline 6 & 500 & $32000(38000)$ \\
\hline 7 & 501 & 0 \\
\hline 8 & 1500 & 0 \\
\hline
\end{tabular}

\section{Dependence heat flux to time}

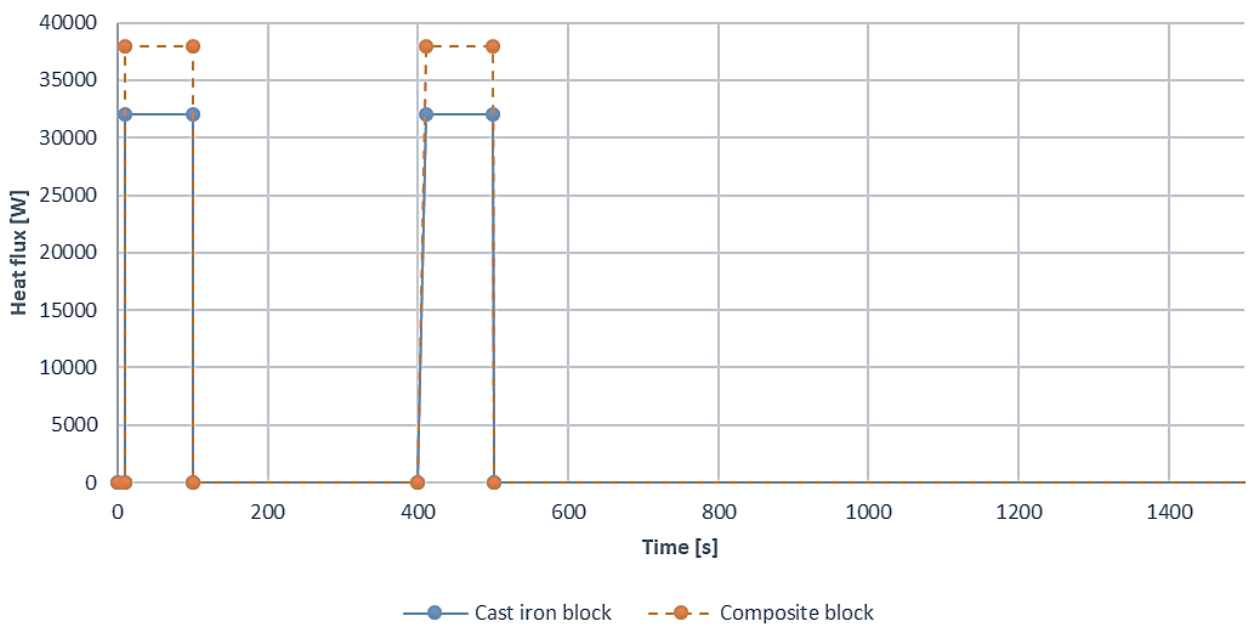

Fig. 2. Dependence of a heat flux to time 


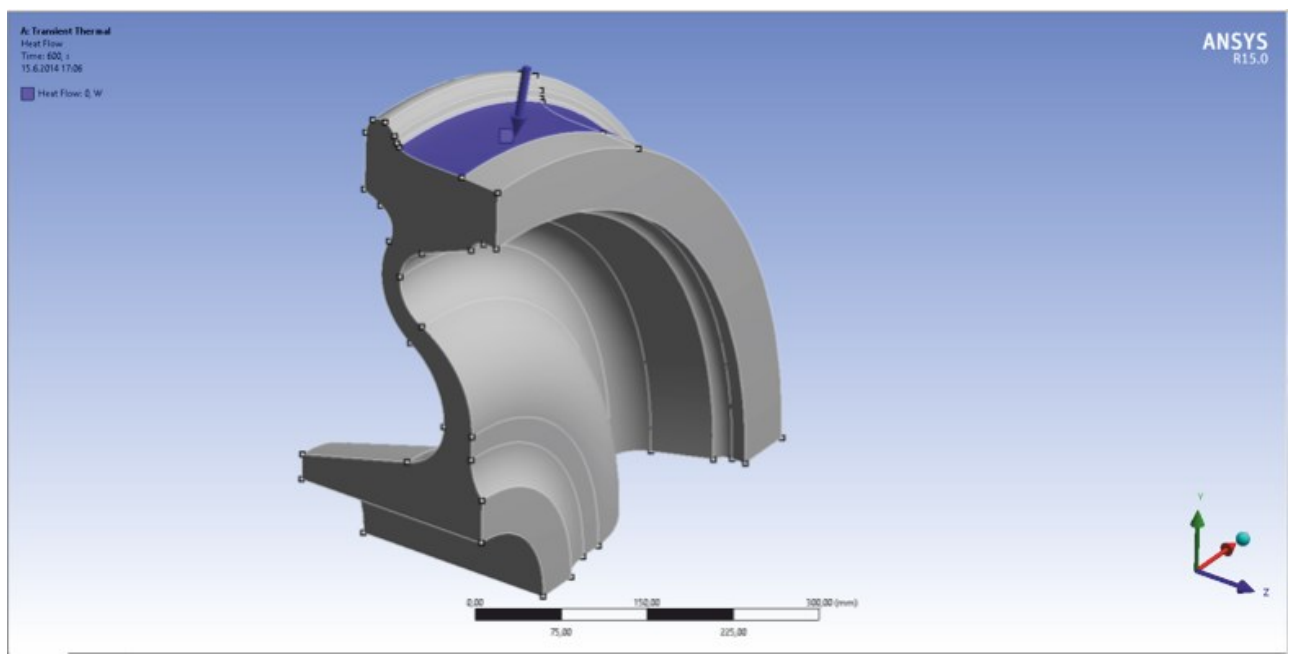

Fig. 3. Heat flux applied to the tread of the rail wheel

Reference ambient temperature was set to $22^{\circ} \mathrm{C}$.

Thermal radiation was set to all areas of railway wheel.

Six degrees of freedom were taken to the railway wheel. (Fig. 4).

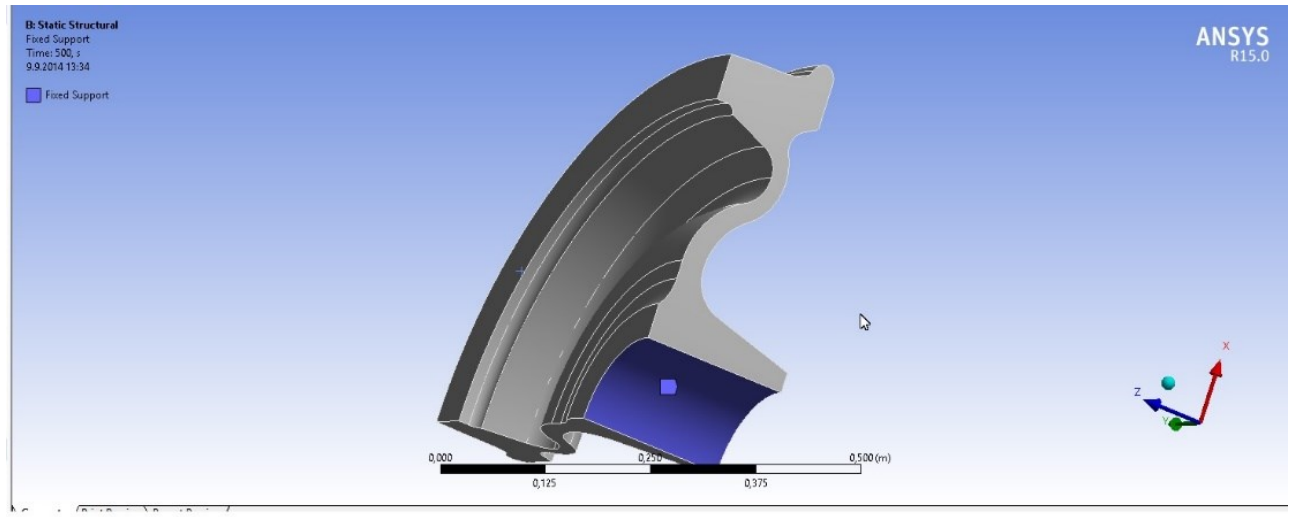

Fig. 4. Applied boundary conditions

Finite element mesh (Fig. 5) was created according to the dimensional parameters with the following parameters:

- element size: $10 \mathrm{~mm}$,

- element type: SOLID 90,

- number of elements: 5075 ,

- number of nodal elements: 26156. 


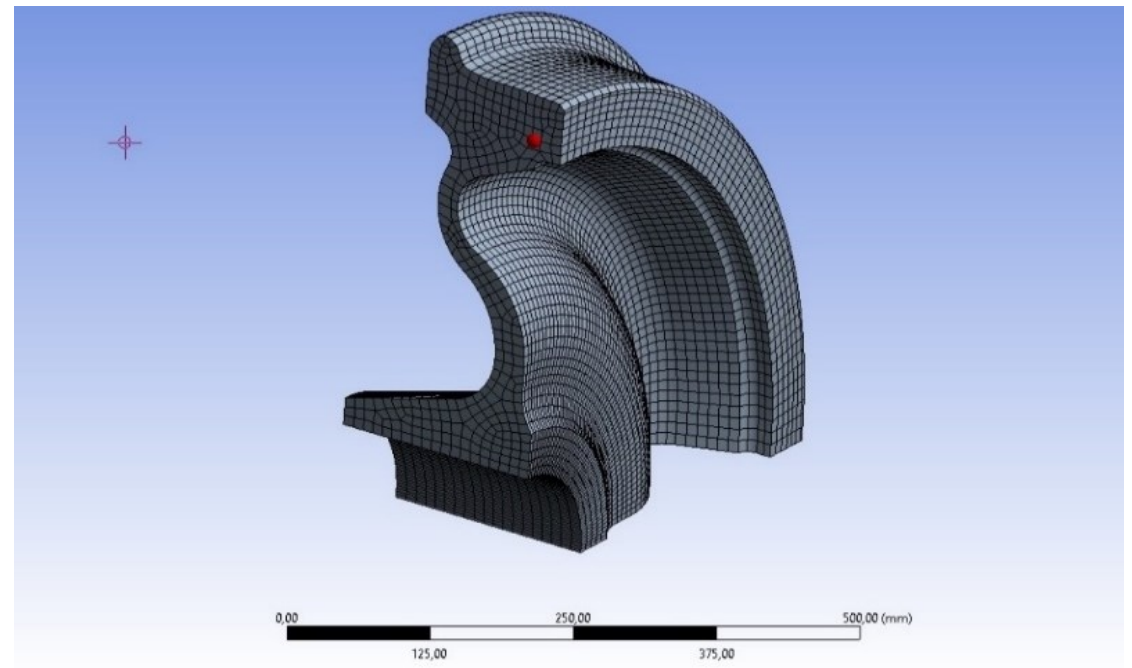

Fig. 5. Finite element model

Setting solver:

- direct solver with fixed setting step and automatic control of convergence.

Computer parameters:

- processor: Intel Core i7 3,3 GHz (6 core)

- memory (RAM): 64 GB

\subsection{Results}

On the basis of the analysis performed, the maximum value of the braking temperature was determined at $485^{\circ} \mathrm{C}$ at 500 seconds due braking by cast iron block, which is at the end of the second braking. The temperature was $143{ }^{\circ} \mathrm{C}$ after cooling. The maximum temperature was determined at 500 seconds at $572{ }^{\circ} \mathrm{C}$ due braking by composite block. The temperature was $164^{\circ} \mathrm{C}$ after cooling.

The temperatures in the cross section of the rail wheel, at selected points (Fig. 6), are shown in Fig. 7 and Fig. 8. These points were chosen so that the distribution of temperatures and stresses in the cross section of the wheel can be monitored.

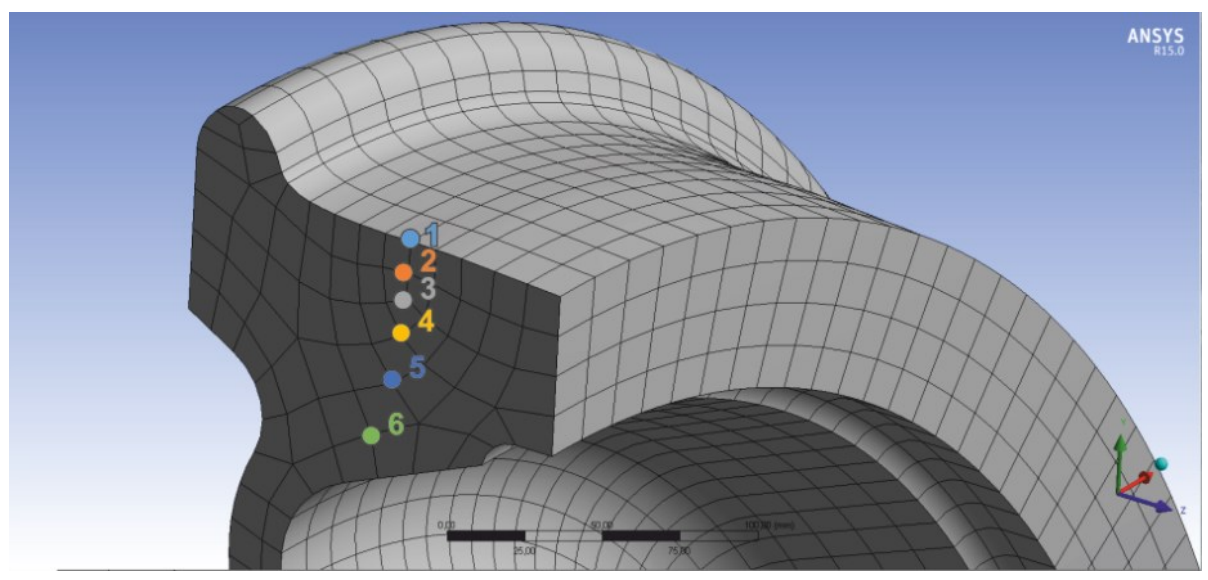

Fig. 6. The selected points, where were evaluated the temperatures and stresses 


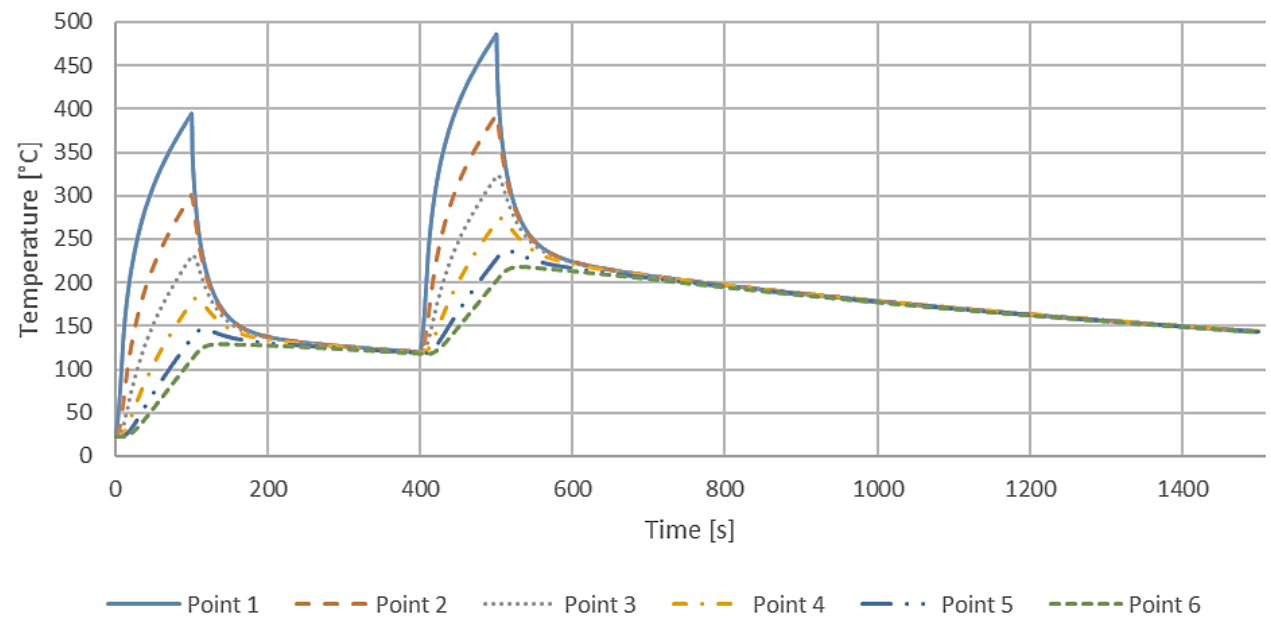

Fig. 7. Dependence temperature to time in selected points - cast iron block

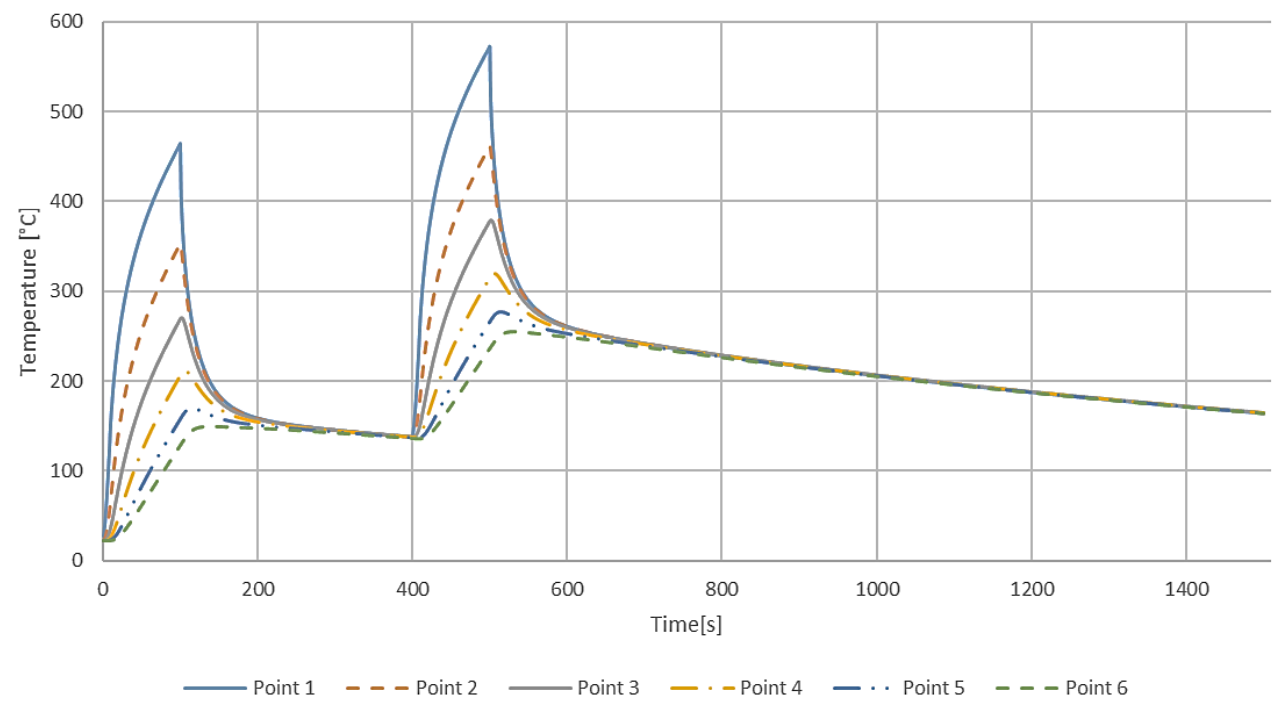

Fig. 8. Dependence temperature to time in selected points - composite block

\section{Calculation of equivalent stress}

On the basis of the thermal transient analysis, it was possible to detect the course of the reduced stresses in the braked railway wheel, which were caused by the thermal load. We could use the parameters from the previous thermal transient analysis thanks the ANSYS program.

Stress value is $90 \mathrm{MPa}$, determined by $\mathrm{HMH}$ theory on the wheel tread in time 1500 seconds. In other measured points, the value is around $24 \mathrm{MPa}$ when braking by cost iron block. Stress value on the wheel tread is $197 \mathrm{MPa}$ in time 1500 seconds, when braking by composite block and in other point is value $29 \mathrm{MPa}$.

The course of the reduced stresses in the cross-section of the railway wheel (Fig. 6) are shown in Fig. 9 and Fig. 10. 


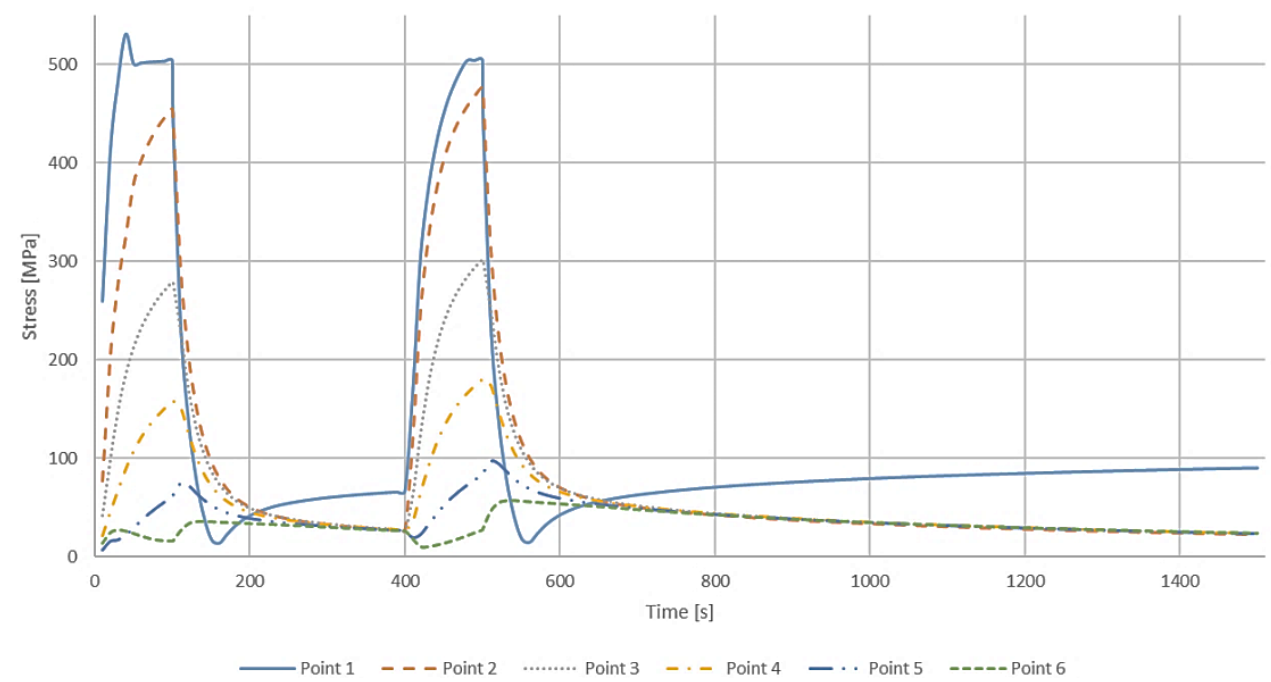

Fig. 9. Dependence stress to time in selected points - cast iron block

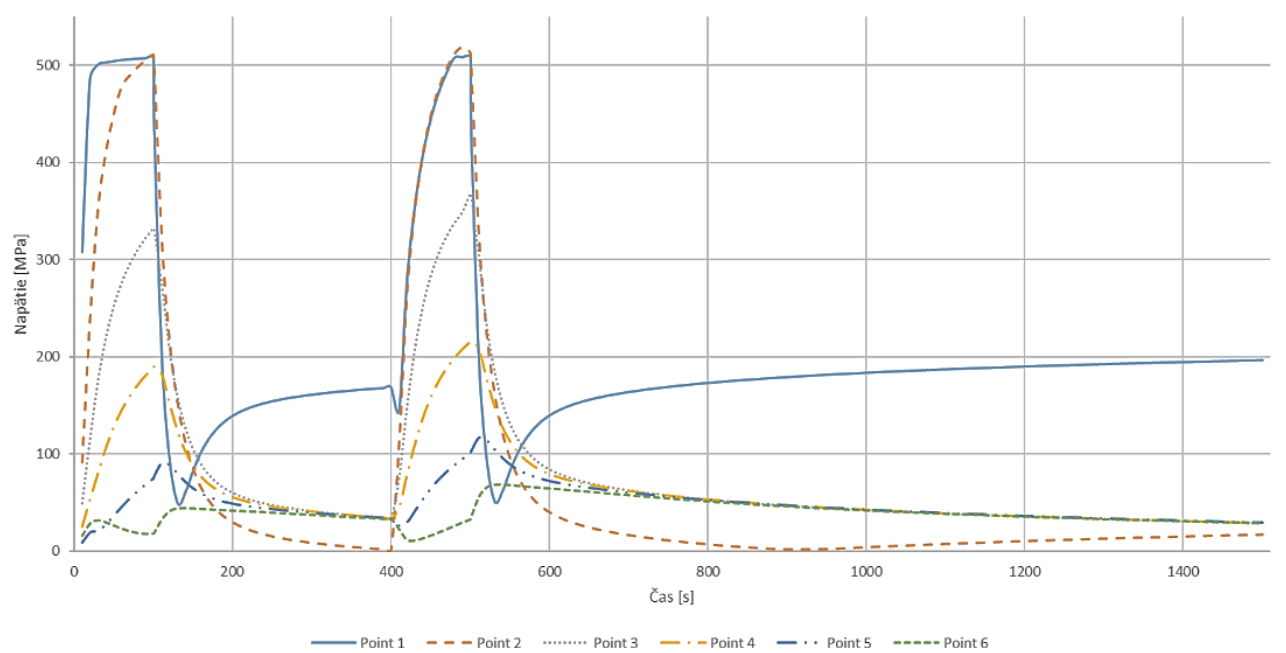

Fig. 10. Dependence stress to time in selected points - composite block

\section{Conclusion}

One possibility for identifying the impact of thermal and mechanical loading on braked railway wheel is the use of appropriate software and implementation of computer analyzes.

The article deals with the detection of structural properties braked railway wheel using a program that uses the finite element method.

On the basis of the thermal transition analysis, when the thermal fields can be determined by braking at constant heat output, a structural analysis was performed when heat inputs from the previous simulation were used as input parameters. Courses of the reduced stresses are results of simulation analyzes generated by thermal load in railway wheel. The next step is to compare the calculated values with the measured values on the 
test stands. It will be necessary to fine-tune the input parameters of the simulation to match the real test values. Our task was to choose the appropriate software to detect stresses based on the temperature fields. This problem was solved in ANSYS program, which proved to be appropriate for the given task type.

The work was supported by the Cultural and Educational Grant Agency of the Ministry of Education of the Slovak Republic in project No. KEGA 077ŽU-4/2017: Modernization of the Vehicles and engines study program. The work was also supported by the project No. APVV-0842-11: Equivalent railway operation load simulator on the roller rig and VEGA No. 1/0927/15: Research of the use of alternative fuels and hybrid drives on traction vehicles with aim to reduce fuel consumption and air pollutants production.

Research-Educational Centre of Rail Vehicles (VVCKV)

\section{References}

1. M. Blatnický, M. Štauderová, J. Dižo, Numerical analysis of the structure girder for vehicle axle scale calibration. Procedia Engineering 177, 510-515 (2017)

2. J. Gerlici, R. Řezníček, Temperature fields in the brake blocks when braking on an incline. In XI. International conference "Current problems in rail vehicles". 233-244, Česká Třebová, [in Slovak] (1994)

3. J. Gerlici, V. Hlavňa, R. Řezníček, Simulation of down hill braking with a shoe brake. $4^{\text {th }}$ mini conference on vehicle system dynamic, identification and anomalies. Technical university of Budapest (1994)

4. J. Gerlici, T. Lack, D. Kalinčák, Laboratory simulation of braking with a shoe brake. In: SITARZ, M.: Railway wheelsets. Monograph. ISBN 83-7335-151-5. Chapter 5, 8392, Silesian university of technology, Gliwice Poland (2003)

5. J. Gerlici, T. Lack, Modified HHT method for vehicle vibration analysis in time domain utilisation. Applied mechanics and materials 486, 396-405 (2014)

6. J. Gerlici, T. Lack, Contact geometry influence on the rail / wheel surface stress distribution. Procedia Engineering, 2249-2257, Elsevier Ltd. (2010)

7. J. Gerlici, T. Lack, Rail vehicles brake components test bench utilisation. Applied mechanics and materials 486, 379-386 (2014)

8. J. Gerlici, T. Lack, Iterative method for railway wheel profile design. Communications: Scientific Letters of the University of Žilina 11 (2), 49-56 (2009)

9. J. Gerlici, T. Lack, Railway wheel and rail head profiles development based on the geometric characteristics shapes. Wear: an international journal on the science and technology of friction, lubrication and wear 271 (1-2), 246-258 (2011)

10. J. Gerlici, T. Lack, J. Harušinec, Realistic simulation of railway operation on the RAILBCOT test stand. Applied mechanics and materials 486, 387-395 (2014)

11. J. Gerlici, T. Lack, Test benches computer control software tools development. Scientific bulletin of North University of Baia Mare: Fascicle: Mechanics, Tribology. Technology of Machine Manufacturing XVII (C), 181-186, Baia Mare (2003)

12. L. Jakubovičová, M. Sága, Computational analysis of contact stress distribution in the case of mutual stewing of roller bearing rings. Novel Trends in Production Devices and Systems, Applied Mechanics and Materials 474, 363-368 (2014)

13. L. Jakubovičová, A. Gašparec, P. Kopas, M. Sága, Optimization of the induction heating process in order to achieve uniform surface temperature. Procedia Engineering 136, 125-131 (2016) 
14. T. Lack, J. Gerlici, Contact area and normal stress determination on railway wheel / rail contact. Communications, the scientific letters of the University of Zilina $\mathbf{1 / 2 0 0 5}$, 38-45 (2005)

15. T. Lack, J. Gerlici, Wheel/rail contact stress evaluation by means of the modified Strip method. Communications: scientific letters of the University of Žilina 15 (3), 126-132 (2013)

16. T. Lack, J. Gerlici, Wheel/rail tangential contact stress evaluation by means of the modified strip method. Communications: scientific letters of the University of Žilina $\mathbf{1 6}$ (3A), 33-39 (2014)

17. T. Lack, J. Gerlici, A modified strip method to speed up the calculation of normal stress between wheel and rail. Applied mechanics and materials 486, 359-370 (2014)

18. T. Lack, J. Gerlici, The FASTSIM method modification in speed up the calculation of tangential contact stresses between wheel and rail. Manufacturing technology: journal for science, research and production 13 (4), 486-492

19. T. Lack, J. Gerlici, A modified strip method to speed up the tangential stress between wheel and rail calculation. Applied mechanics and materials 486, 371-378 (2014)

20. T. Lack, J. Gerlici, The usage of arcs radii profile variation for the synthesis of railway wheel and rail head profiles. Communications - scientific letters of the University of Žilina 8 (2), 57-69 (2006)

21. K. W. Man, Contact mechanics using boundary elements. Topics in engineering. Volume 22. (Computational mechanics publication, ISBN 185312334 X, 185. p, Southampton, 1994)

22. R. Řezníček, J. Gerlici, T. Lack, Stress analysis monoblock wheels braked by FEM. Proceedings: ŽELSEM '93, Savings in railway", University of Zilina 1993, 155-161, Loučeň, In Slovak (1993)

23. A. Sapietová, M. Sága, P. Novák, R. Bednár, J. Dižo, Design and application of multisoftware platform for solving of mechanical multi-body system problems. Mechatronics: Recent technological and scientific advances, 345-354 (2011)

24. A. Suchánek, J. Gerlici, J. Harušinec, T. Lack, Analysis of temperature distribution in a braked railway wheel during braking by the brake block. TRANSCOM 2013, section 6, 289-292. EDIS Publishing Institution of the University of Zilina, ISBN 978-80-5540695-4 (2013)

25. Vlk, et al., Experimental mechanics. Chapter 6.1 Introduction into experimental determination of residual stresses. Brno university of technology, 119-123 [in Czech] 